\title{
ARTÍCULOS
}

\section{EL TERRORISMO DE ESTADO EN ARGENTINA (1976-1983). REFLEXIONES EN TORNO A LAS PRÁCTICAS DE VIOLENCIA CONTRA LAS MUJERES EN LOS CAMPOS DE CONCENTRACIÓN.}

\author{
Julio Lisandro Cañón Voirin \\ Universidade de Santiago de Compostela \\ juliolisandro.canon@gmail.es
}

\begin{abstract}
Resumen: Este trabajo, propone un acercamiento a una dimensión de las prácticas del terrorismo de Estado en Argentina: la tortura en los campos de concentración. Más específicamente, sobre la tortura que padecieron las mujeres durante su cautiverio. Para ello, analizamos la experiencia de cuatro militantes políticas, secuestradas en la provincia de Entre Ríos. El trabajo repasa tres momentos bien diferenciados, el antes, el durante y el después del terrorismo de Estado. Cada uno de ellos, permite entender cómo se modifican las estructuras objetivas del Estado para exterminar a los grupos reducidos a una otredad negativizada.
\end{abstract}

Palabras clave: Terrorismo de Estado, Argentina, dictadura, violencia, mujeres, tortura.

Tittle: STATE TERRORISM IN ARGENTINA. REFLECTIONS REGARDING VIOLENCE PRACTICES AGAINST WOMEN IN CONCENTRATION CAMPS.

Abstract: This paper proposes an approach to a dimension of the practices of State terrorism in Argentina: torture in the concentration camps. More specifically, about the torture suffered by women during their captivity. For this, we analyze the experience of four political activists, kidnapped in the province of Entre Ríos. The text reviews three distinct moments, the before, during and after State terrorism. Each one of them allows, without deflating the magnitude of what happened, understanding how the objective structures of the State are modified to exterminate the reduced groups to a negativized otherness.

Keywords: State Terrorism, Argentina, dictatorship, violence, women, torture.

\section{Aldaba}

Si algo distingue al Estado moderno y, al mismo tiempo, lo diferencia de los tipos de estado que le precedieron, es haber conseguido el monopolio de la violencia. Esa potestad le permite contar con todos los recursos posibles de la legalidad para implementar medidas de represión, bajo el control de las instituciones de coerción. Sin embargo, la realidad ha demostrado que los estados pueden liberarse de las

Recibido: 03-02-2020

Aceptado: 06-02-2020

Cómo citar este artículo: CAÑÓN VOIRIN, Julio Lisandro. El terrorismo de Estado en Argentina (1976-1983). Reflexiones en torno a las prácticas de violencia contra las mujeres en los campos de concentración. Naveg@mérica. Revista electrónica editada por la Asociación Española de Americanistas [en línea]. 2020, n. 24. Disponible en: <http://revistas.um.es/navegamerica>. [Consulta: Fecha de consulta]. ISSN 1989-211X. 
limitaciones correlativas al Estado de derecho y aplicar una violencia racionalmente dirigida para eliminar, destruir o cuando menos debilitar a determinados grupos humanos. Esto, que supone una alteración fundamental en los principios éticos del Estado, es lo que sucedió en Argentina, entre 1976 y 1983, bajo la dictadura del autodenominado Proceso de Reorganización Nacional (PRN). En efecto, a la actividad contemplada en el marco jurídico del Estado de derecho, la dictadura incorporó una actividad paralela y al margen de toda legalidad formal, con el crimen selectivo y masivo como método fundamental ${ }^{1}$.

Claro que, como ya han demostrado algunas investigaciones ${ }^{2}$, no es tan solo una cuestión de técnicas represivas, sino un nuevo modelo estatal, una forma particular del estado de excepción permanente. Esto es, a decir de Agamben ${ }^{3}$, la suspensión del orden jurídico, que posibilita la eliminación física no sólo de los adversarios políticos sino de categorías enteras de ciudadanos que, por cualquier razón, resultan no integrables en el sistema político. Yendo un poco más allá de lo que plantea Agamben, para que el estado de excepción dé lugar a una de sus manifestaciones más violentas, el terrorismo de Estado, es necesario centrarse en la capacidad performativa ${ }^{4}$ de los discursos que niegan la condición no ya de ciudadanos, sino de seres humanos, a los grupos que serán eliminados. Es decir, para que la aniquilación de un grupo pueda ser practicada, es necesaria su definición previa, y esa definición debe ser en términos de deshumanización. No solo debe ser considerado indeseable y carente de las condiciones para pertenecer a la comunidad nacional, sino que debe ser desposeído de la condición humana. Las potenciales víctimas deben ser desubjetivizadas mediante la consideración de inferioridad en su estatuto de ser, pensar y obrar, expulsándolas hacia la inhumanidad ${ }^{5}$.

Partiendo de lo anterior, y siguiendo a Hannah Arendt, podemos decir que el PRN constituyó un régimen, en el cual el terror dejó de ser un simple medio para la supresión de la oposición, "cuyo objetivo último no es el bienestar de los hombres o el interés de un solo hombre, sino la fabricación de la Humanidad, elimina a los individuos en favor de la especie"6. Desde esta perspectiva, el PRN comparte, tanto

1 DUHALDE, Eduardo Luis. El Estado terrorista argentino. Buenos Aires: El Caballito, 1983; CALVEIRO, Pilar. La experiencia concentracionaria. En: YANKELEVICH, Pablo (comp.). Argentina, 1976: estudios en torno al golpe de Estado. Buenos Aires: Fondo de Cultura Económica, 2008.

${ }^{2} \mathrm{Al}$ respecto puede consultarse el dossier Violencia estatal, persecutoria, ideologías, terrorismo de estado y genocidio. Confluenze, Rivista di studi iberoamericani. 2018, vol. X, n. 2. En particular: CAÑÓN VOIRIN, Julio Lisandro. El Estado terrorista en América. Una historización sobre su configuración, pp. 4-33; y ROMÁN YÁÑEZ, César Manuel. Crítica a la concepción inmanentista de la violencia política y perspectivas sobre el terrorismo de Estado y el genocidio en la Argentina reciente. Dossier Violencia estatal, persecutoria, ideologías, terrorismo de estado y genocidio. Confluenze, Rivista di studi iberoamericani. 2018, vol. X, n. 2, pp. 57-79. Como así también, las distintas comunicaciones presentadas en el I Encuentro Internacional de Estudios sobre Estados de Excepción y terrorismo de Estado [en línea]. Santiago de Compostela, 13-14 de noviembre de 2018. [Fecha de consulta: 02/05/2019]. Disponible en <https://redredet.wordpress.com/>.

${ }^{3}$ AGAMBEN, Giorgio. Estado de Excepción, Homo sacer, II, I. Buenos Aires: Adriana Hidalgo, 2004.

${ }_{5}^{4}$ AUSTIN, John. How to Do Things with words. Cambridge: Harvard University Press, 1975.

${ }^{5}$ FEIERSTEIN, Daniel. El genocidio como práctica social. Entre el nazismo y la experiencia argentina. Buenos Aires: Fondo de Cultura Económica, 2007.

${ }^{6}$ ARENDT, Hannah. Los orígenes del totalitarismo. Buenos Aires: Taurus, 1998, p. 372. 
como régimen y como forma de Estado, con otras dictaduras de la región el haber modificado las estructuras del Estado para violar sistemáticamente los derechos consagrados en la Declaración Universal de los Derechos Humanos (1948), en el Pacto Internacional de Derechos Civiles y Políticos (1976), en la Convención Interamericana sobre Derechos Humanos (1969), así como en la Constitución Nacional en lo que se refiere a garantías individuales ${ }^{7}$.

Sin dudas, un primer análisis de lo anterior arroja, como mínimo, un balance demoledor para toda la humanidad, y nos obliga a pensar el terrorismo de Estado. Debemos preguntarnos por las lógicas de los campos de concentración del PRN, por sus estrategias de exterminio. Es urgente pensarlo, acorralarse, entrar en el abismo del horror, enfrentar una insoslayable realidad: tras el terrorismo de Estado, la Historia es otra historia. Es la historia que le sigue a los asesinatos, a las torturas, a las desapariciones. La opresión radical, significante indisoluble del terrorismo de Estado, implica un quiebre, quizás tan profundo como aquel, en otro sentido: los agentes de castigo que llegan con él.

La metódica frialdad con la que se planificaron los complejos represivos ${ }^{8}$, instalados por toda la geografía argentina y la existencia de un accionar masivo, deliberado y sistemático -secuestro, tortura, asesinato y desaparición-, que anuló el deber estatal de velar por la integridad de todas las personas, dan cuenta de las decisiones político-militares que configuraron un aparato represivo extremo, terrorista. Todo fue planeado al detalle.

El PRN dividió al país en diferentes zonas, subzonas y áreas. En las principales guarniciones militares, comisarías y edificios de las Fuerzas Armadas se establecieron campos de concentración, con salas de tortura y espacios para alojar a los cientos de secuestrados que, todos los días, ingresaban a la feroz maquinaria represiva. Para 1976, ya están funcionando más de la mitad de los setecientos sesenta y dos campos que existieron durante todo el período del PRN.

Las detenciones, mejor dicho, los secuestros se realizaron de forma absolutamente ilegal. Estos se llevaron a cabo en las viviendas particulares, en los lugares de trabajo, o en la misma vía pública, muchas veces a plena luz del día. Los llamados Grupos de Tareas eran los encargados de realizar los secuestros. Antes de efectuar el operativo, los jefes del grupo, pedían "zona liberada", para no cruzarse con la policía $u$ otras fuerzas de seguridad. Una vez secuestrado, el detenido/desaparecido, era trasladado al campo de concentración; allí, se le tortura.

\footnotetext{
7 El campo de violación de los derechos humanos abarcó, en Argentina, según la Comisión Interamericana de Derechos Humanos de la O.E.A.: violaciones del derecho a la vida, del derecho a la libertad, del derecho a la seguridad e integridad personal, del derecho de justicia y proceso regular, del derecho a la libertad de opinión, expresión e información, de los derechos laborales, de los derechos políticos, de los derechos de libertad religiosa y de cultos. Organización de Estados Americanos. Informe sobre la situación de los derechos humanos en Argentina [en línea]. O.E.A., abril 1980. [Fecha de consulta: 19/02/2019]. Disponible en $<$ http://www.cidh.oas.org/countryrep/Argentina80sp/indice.htm>.

8 Empleamos aquí, la noción formulada por César Román en su ponencia: Los Centros de Exterminio en la Argentina del Estado Terrorista, 1976-1983. Notas para una primera reflexión. Presentada en el I Encuentro Internacional de Estudios... Op. cit.
} 
No solo para obtener información, sino también para destruirlo en su subjetividad individual y colectiva.

De este modo, nos situamos ante nuestro objeto de estudio, indagar en la especificidad de la violencia contra las mujeres, mientras estuvieron en cautiverio. La Convención Interamericana para Prevenir, Erradicar y Sancionar la Violencia contra la Mujer sintetiza de manera clara lo que, aquí, entendemos como violencia contra la mujer: "cualquier acción o conducta, basada en su género, que cause muerte, daño o sufrimiento físico, sexual o psicológico a la mujer" ${ }^{\prime \prime}$. Abordaremos la experiencia de cuatro militantes políticas en los campos de concentración de la ciudad de Paraná (capital de la provincia de Entre Ríos) ${ }^{10}$. Por su condición de mujeres, en el marco de las violaciones a los Derechos Humanos, sufrieron una forma particular de tortura: la violencia sexual. La Organización Mundial de la Salud define como violencia sexual: "todo acto sexual, la tentativa de consumar un acto sexual, los comentarios o insinuaciones sexuales no deseados, o las acciones para comercializar o utilizar de cualquier otro modo la sexualidad de una persona mediante coacción por otra persona"11. Si bien, la definición no distingue sexo u orientación sexual, es un hecho cierto que, este tipo de violencia casi exclusivamente se perpetra contra mujeres.

Ahora bien, la violencia sexual, como violencia específica contra las mujeres, interesa a los fines de este trabajo en tanto tortura. Esta es definida por la Convención Interamericana para prevenir y sancionar la tortura, como: "todo acto realizado intencionalmente, por el cual se inflijan a una persona penas o sufrimientos físicos o mentales [...]. Se entenderá también como tortura la aplicación sobre una persona de métodos tendientes a anular la personalidad de la víctima o a disminuir su capacidad física o mental’12.

Ha sido el Manual de Investigación y Documentación Efectiva sobre Tortura, Castigos y Tratamientos Crueles, Inhumanos o Degradantes (1999), conocido como Protocolo de Estambul, el que cualificó y detalló la violencia sexual, como forma de tortura: "La tortura sexual empieza por la desnudez forzada, [...]. La desnudez aumenta el terror psicológico de todos los aspectos de la tortura pues abre siempre la posibilidad de malos tratos, violación o sodomía. Además, las amenazas verbales, los insultos y las burlas sexuales forman parte de la tortura sexual pues incrementan la humillación y sus aspectos degradantes, todo lo cual forma parte del procedimiento. Para la mujer el toqueteo es traumático en todos los casos y se

\footnotetext{
9 Organización de Estados Americanos. Convención Interamericana para Prevenir, Erradicar y Sancionar la Violencia contra la Mujer [en línea]. OEA, 1994. [Fecha de consulta: 19/02/2019]. Disponible en <http://www.oas.org/es/mesecvi/docs/Folleto-BelemdoPara-ES-WEB.pdf>.

${ }_{10}$ Hemos entrevistado a cuatro mujeres, militantes políticas, cada una con su propia adscripción ideológica. Acordamos con las entrevistadas, cambiar sus nombres. Las entrevistas fueron realizadas en el mes de agosto del año 2012. Los detalles de cada entrevista se recogen al final de la bibliografía.

${ }_{11}$ Organización Panamericana de la Salud. Informe mundial sobre la violencia y la salud: resumen. Washington: Oficina Regional para las Américas de la Organización Mundial de la Salud, 2002.

${ }_{12}$ Organización de Estados Americanos. Convención Interamericana para Prevenir y Sancionar la Tortura [en línea]. OEA, 1985. [Fecha de consulta: 19/02/2019]. Disponible en $<$ http://www.oas.org/juridico/spanish/tratados/a-51.html >.
} 
considera tortura"13.

Todo lo anterior, nos permite fundamentar nuestro objetivo: situar la violencia, los abusos y las agresiones sexuales en el ámbito de los crímenes contra la humanidad. Creemos que ello contribuirá a generar discursos que aporten a la transmisión sobre hechos históricos, cuyas consecuencias afectan al conjunto social. Y si bien es cierto que, la responsabilidad por los crímenes del PRN es propia de quienes los perpetraron (intelectual y materialmente), el ciudadano contemporáneo, para no ser cómplice, no debe participar con asentimiento pasivo ante la impunidad.

El trabajo que aquí se presenta se propone tres objetivos. Primero, contribuir al conocimiento de las prácticas de violencia que desencadenó el terrorismo de Estado en la Argentina. Segundo, establecer una relación entre el terrorismo de Estado y la memoria social posterior y anterior a la última dictadura. Finalmente, analizar y caracterizar la violencia específica sobre las mujeres en el marco del terrorismo de Estado. La unidad de análisis será la experiencia de cautiverio de cuatro militantes políticas secuestradas en la provincia de Entre Ríos.

Estructuramos el texto en tres apartados principales. En cada uno de ellos, abordamos diferentes dimensiones del tema objeto de estudio. Para ello, empleamos un corpus documental de fuentes de diverso tipo -legislación, causas judiciales, entrevistas orales, documentos militares-, que serán puestas en relación con el material bibliográfico escogido.

\section{Del terrorismo de Estado y su después}

En sus Tesis de filosofía de la historia (1940), Walter Benjamin, nos convida a reflexionar sobre las narrativas hegemónicas que se impusieron en el discurso histórico. Podemos sumarnos a ese desafío, a través de un conjunto de interrogantes, que se nos antojan pertinentes: ¿hay una sola forma de hacer historia? Y, ¿esa forma es siempre la forma de los vencedores? Pero si la Historia la escriben los que ganan, ¿qué pasa con las historias derrotadas?, ¿logran o no logran redimirse? Con relación a ello, Benjamin, en una de sus tesis, dice: "El don de avivar en lo pasado la chispa de la esperanza reside sólo en aquel historiador que está penetrado de lo siguiente: ni siquiera los muertos estarán seguros si el enemigo vence" ${ }^{14}$. Y para Benjamin no ha dejado de vencer, pero en todo caso, si el enemigo vence también desaparecerán los testimonios de los vencidos. Por eso, la disputa por quién escribe la historia no es, ni mucho menos, un elemento irrelevante. No se trata de un simple juego entre profesionales de la Historia. De lo que estamos hablando, es de la posibilidad de una justicia real.

Para mirar el mundo por venir, Benjamin, dirige su mirada hacia atrás. Porque lo que debemos hacer en el futuro, si estamos intentando construir un mundo más justo, es redimir a todos los muertos de la historia, que fueron doblemente asesinados. Por una parte, fueron derrotados, y por otra, sus testimonios fueron

\footnotetext{
${ }^{13}$ Naciones Unidas. Protocolo de Estambul. Manual de Investigación y Documentación Efectiva sobre Tortura, Castigos y Tratamientos Crueles, Inhumanos o Degradantes. Ginebra: ONU, 2004, p. 79.

${ }^{14}$ BENJAMIN, Walter. Tesis sobre la historia y otros fragmentos. México: UA, 2008, p. 21.
} 
disueltos. En ese sentido, es necesario estar alertas ante el giro hacia un pasado ficcionalizado. Este, conteniendo un relato convenientemente conciliador y lleno de convenciones tranquilizadoras, es un fenómeno particularmente sospechoso. Mas, el giro a la memoria puede significar más que un síntoma, al menos cuando la preocupación incluye el deseo de ocuparse del problema de la historia en la medida en que pesa sobre el presente y el futuro ${ }^{15}$. Si nos centramos en el terrorismo de Estado, como un fenómeno situado en el punto de intersección entre historia y memoria, podemos inquirirnos en cómo pensarlo. Por ende, lo primero, es recuperar los presupuestos que rescatan lo ocurrido, y permiten ponerlo a salvo de aquellos que lo colocan en los territorios de lo inenarrable, como un signo de lo superado.

En Argentina, los propios responsables del terrorismo de Estado quisieron administrar la memoria de lo ocurrido, buscaron la derogación de la memoria colectiva, proponiendo institucionalmente el olvido ${ }^{16}$. Deseosos de cimentar el olvido y la impunidad, quisieron clausurar una realidad que aún no se había constituido en pasado. Sin embargo, con el cambio de régimen, marcado por el fin de la dictadura y el retorno de la legalidad constitucional (1983), debieron dar cuenta de sus actos ante los tribunales de justicia. A los pocos días de asumir la primera magistratura del país, el presidente Alfonsín (1983-1989) habilitó el inició de las investigaciones judiciales, respecto de lo actuado por las tres juntas militares que se sucedieron durante el PRN ${ }^{17}$. En gran medida, ello fue posible, por la acción inclaudicable de los organismos de Derechos Humanos y por los sobrevivientes que pudieron, quisieron y se atrevieron a exigir el esclarecimiento de lo ocurrido.

Asimismo, y con el objetivo de "aclarar los trágicos acontecimientos en los que miles de personas desaparecieron"18, el gobierno creó la Comisión Nacional Sobre la Desaparición de Personas (CONADEP). Su misión principal fue: esclarecer los hechos relacionados con la desaparición de personas, mediante la recepción de denuncias y pruebas sobre las desapariciones ocurridas en el país entre 1976 y 1983. Una vez concluida su tarea, la CONADEP, presentó (septiembre de 1984) un voluminoso informe: Nunca Más. Las casi quinientas páginas que lo componen constituyen un detallado y sólido material probatorio, sobre la infraestructura estatal que sustituyó la ley por el terror.

Por su parte, la causa judicial, conocida como el Juicio a las Juntas (abrildiciembre 1985), verificó la sórdida trama del terrorismo de Estado. La fiscalía escogió para elevar a juicio, por su grado de representatividad, setecientos casos de

\footnotetext{
${ }^{15}$ LA CAPRA, Dominick. Historia y Memoria después de Auschwitz. Buenos Aires: Prometeo, 2008.

${ }^{16}$ Véase, Ley № 22.924/1983, de 23 de marzo. Ley de Pacificación Nacional. Medidas políticas y normativas tendientes a sentar las bases de la definitiva pacificación del país. Boletín Oficial de la República Argentina, 27 de septiembre de 1983, núm. 25266. Otro documento de interés: Junta Militar. Documento final de la Junta Militar sobre la guerra contra la subversión y el terrorismo. Buenos Aires: La Junta, 1983.

17 Decreto № 158/1983, de 13 de diciembre. Acciones penales. Sométese a juicio sumario ante el Consejo Superior de las Fuerzas Armadas a los integrantes de la Junta Militar que usurpó el gobierno de la Nación el 24 de marzo de 1976 y a los integrantes de las dos Juntas Militares subsiguientes. Boletín Oficial de la República Argentina, 25 de diciembre de 1983, núm. 25.321, p.5.

${ }_{18}$ Decreto № 187/1983, de 15 de diciembre. Comisión Nacional sobre la Desaparición de Personas. Boletín Oficial de la República Argentina, 19 de diciembre de 1983, núm. 25.325, p. 1.
} 
desapariciones -recordemos que la CONADEP había certificado la existencia de casi 9000 casos de desapariciones forzosas, señalando que dicho número era provisional y que sin duda el número sería mayor-. Sobre ellos, se pronunció la Cámara Federal de la Capital en lo Criminal y Correccional. En este punto, es importante subrayar que no se trató de tribunales especiales, sino de la justicia ordinaria, la misma que, los enjuiciados, se habían negado a aplicar durante los años que estuvieron en el poder. Ahora, sancionar a los responsables de las violaciones de los Derechos Humanos, significaba erradicar los efectos perversos de la impunidad.

Los miembros de las Fuerzas Armadas y de Seguridad se opusieron férreamente, a la continuación de los procesos judiciales. Su resistencia, amenazas e intimidaciones, que atenazaban la continuidad democrática, dieron lugar a dos leyes: 23.492 (1986) y 23.521 (1987), conocidas como Punto Final y Obediencia debida, respectivamente. Ambas leyes, no solo clausuraron la vía judicial, sino que inauguraron una lógica político-estatal que subordinaba la centralidad de los Derechos Humanos a la necesidad de gobernabilidad, consenso y crecimiento económico. Durante la administración menemista (1989-1999) ganó centralidad el discurso de la reconciliación nacional. Un claro intento de sofocar el recuerdo e instalar un silencio aliado de la impunidad. Era, ni más ni menos, el pensamiento programático del olvido que dio sustento a los indultos presidenciales de 1989 y $1990^{19}$.

Mas, el intento estatal por desprenderse del incómodo pasado, comenzó a agrietarse entre 1994 y 1995. La Comisión de Acuerdos del Senado, responsable de resolver sobre los ascensos militares, recibió en 1993 los pliegos para tratar los casos de los capitanes de la Marina Antonio Pernías y Juan Carlos Rolón. Los dos marinos habían sido denunciados por pertenecer a los Grupos de Tareas de la Escuela Superior de Mecánica de la Armada. En octubre de 1994, Rolón y Pernías prestaron declaración ante la Comisión; allí reconocieron los métodos aplicados durante la dictadura: tortura, asesinato y desaparición ${ }^{20}$. Hasta ese momento, los militares habían rechazado y negado la existencia de dichos métodos. Pocos meses después, el capitán de corbeta Adolfo Scilingo, en una entrevista, confesaba que los secuestrados de la Escuela Superior de Mecánica de la Armada, eran arrojados a las aguas del Río de La Plata, desde aviones en vuelo: los vuelos de la muerte ${ }^{21}$. Años más tarde, el exdictador Videla reconocía, refiriéndose a los secuestrados: "Había que desaparecerlos [...] ¿Dar a conocer dónde están los restos? Pero ¿qué es lo que podíamos señalar? ¿El mar, el Río de la Plata, el Riachuelo?"22.

Al mismo tiempo, se iniciaban causas judiciales por supuestos no contemplados en las leyes de Punto Final y Obediencia Debida, ni en los indultos: la apropiación de

\footnotetext{
${ }^{19}$ Los indultos beneficiaron a los militares procesados que no habían sido favorecidos por las leyes de Punto Final y Obediencia Debida; y a los condenados en el Juicio a las Juntas.

${ }^{20}$ AZNAREZ, Juan Jesús. Denegado el ascenso a dos marinos argentinos. El País. 28/10/94.

${ }^{21}$ VERTBISKY, Horacio. La solución final. Página 12 [en línea]. 03/03/95. [Fecha de consulta: 20/02/2019]. Disponible <https://www.pagina12.com.ar/especiales/20aniversario/la solucion final.html>. ${ }_{22}^{2}$ SEOANE, María y MULEIRO, Vicente. El Dictador. La historia secreta y pública de Jorge Rafael Videla. Buenos Aires: Sudamericana, 2001, p. 215.
} 
menores nacidos de madres en cautiverio. El pasado rememorado volvía y el recurso al olvido se diluía, los tribunales de Argentina reconocían el derecho de las víctimas a conocer la verdad, mediante los Juicios por la Verdad (1998). Estos juicios, que no podían condenar penalmente, tenían como objetivo conocer la suerte de los desaparecidos. Finalmente, en septiembre de 2003, las leyes de Punto Final y Obediencia Debida fueron declaradas nulas, habilitando el reinicio de las investigaciones judiciales (2006) respecto de los crímenes contra los derechos humanos, durante la dictadura ${ }^{23}$.

Tanto en los testimonios recogidos por la CONADEP, como en el Juicio a las Juntas, las mujeres contaron la violencia específica que sufrieron durante el terrorismo de Estado. Pero, no fue sino hasta octubre de 2011, cuando la Unidad Fiscal de Coordinación y Seguimiento de las Causas por Violaciones a los Derechos Humanos cometidas durante el terrorismo de Estado destacó que "los abusos sexuales cometidos en el marco del terrorismo de Estado aún no reciben el tratamiento jurídico adecuado en la práctica judicial" y concluyó que "deben ser considerados crímenes contra la humanidad" ${ }^{24}$.

\section{Del terrorismo de Estado y su antes}

En el campo de las ciencias sociales, existe un cierto consenso respecto de que los regímenes de facto anteriores al PRN se corresponden con un modelo clásico de gobierno militar ${ }^{25}$. De acuerdo con las principales investigaciones referidas al particular, las dictaduras habidas hasta ese momento pueden ser encuadradas en la tipología de régimen autoritario transitorio, cuya característica fundamental sería la concentración de las facultades decisorias del Estado ${ }^{26}$. Es decir, dichos regímenes significaban una interrupción momentánea de las libertades civiles y políticas del ordenamiento social del país, y un incremento de las tareas represivas.

Sin embargo, al promediar los años sesenta del siglo pasado, se produjo un cambio doctrinal en el perfil del intervencionismo militar. Fundamentales para comprender dicho cambio son: la Doctrina de la Seguridad Nacional y la Doctrina de

\footnotetext{
${ }^{23}$ Ley № 25.779/2003, de 21 de agosto. Decláranse insalvablemente nulas las Leyes Nros. 23.492 y 25.521. Boletín Oficial de la República Argentina, núm. 30.226, p. 1.

${ }^{24}$ Procuración General de la Nación. Unidad Fiscal de Coordinación y Seguimiento de las Causas por Violaciones a los Derechos Humanos cometidas durante el Terrorismo de Estado. Consideraciones sobre el juzgamiento de los abusos sexuales cometidos en el marco del terrorismo de Estado [en línea]. 7 de octubre de 2011. [Fecha de consulta: 20/02/2019]. Disponible en https://www.mpf.gob.ar/docs/RepositorioW/DocumentosWeb/LinksNoticias/Delitos sexuales terrorism o de Estado.pdf; POTASH, Robert. El ejército y la política argentina. Buenos Aires: Sudamericana, 1994.

${ }^{25}$ En Argentina, durante el siglo XX, hubo seis regímenes de facto, a saber: 1930-1932; 1943-1946; 1955-1958; 1962-1963; 1966-1973; 1976-1983.

${ }^{26}$ O'DONELL, Guillermo. El Estado Burocrático Autoritario. Triunfo, derrotas y crisis. Buenos Aires: Editorial de Belgrano, 1972; ROUQUIÉ, Alain. El Estado militar en América Latina. Buenos Aires: Emecé, 1984; TOURAINE, Alaine. América Latina: Política y Sociedad. Madrid: Espasa-Calpe, 1982; TAPIA VALDÉS, Jorge. El terrorismo de Estado: La Doctrina de la Seguridad Nacional en el Cono Sur. México: Nueva Imagen, 1980.
} 
la Guerra Moderna ${ }^{27}$. Una y otra importaron una redefinición en el modo de entender los conflictos bélicos, ya que desplazaron el clásico enfrentamiento entre estados, hacia uno entre individuos; y la pelea por el control territorial hacia el control ideológico de la sociedad. Como sea, la nueva doctrina contradecía las bases fundamentales del Estado moderno capitalista. En tanto, consideró que el principio de legalidad, el respeto al contenido esencial de los derechos fundamentales y el control jurisdiccional de los mismos, retaceaban la potestad estatal para mantener el sistema clasista establecido.

Desde finales de los años cincuenta, la formación militar se centró en la contrainsurgencia y la contrarrevolución. La Escuela Superior de Guerra de Argentina, responsable de la preparación de los oficiales del Estado Mayor, incorporó, tal como lo reconocía su director, "nuevas doctrinas y materias a los planes, como consecuencia de la evolución de la guerra moderna"28. Más aún, desde 1957 la Escuela contó con una misión permanente de asesores franceses que, como veteranos del ejército colonial en Indochina y Argelia, transmitieron su experiencia en la contrainsurgencia: "los profesores tocaban siempre el tema de la guerra revolucionaria. Era algo totalmente nuevo para nosotros. En América Latina, no conocíamos ese tipo de problemas. Había luchas políticas, a veces violentas, pero no subversivas. [...] Para nosotros, sólo existía la guerra clásica"29. En ese horizonte, se inscribe la realización del Curso Interamericano de Guerra Contrarrevolucionaria (1961, Buenos Aires) ${ }^{30}$. Su objetivo era la capacitación en el planeamiento, conducción y ejecución de la contrarrevolución, o como dijo el director del Curso: "el estudio de los métodos de lucha contra el más grande enemigo de nuestra forma de vivir, el comunismo"31.

Desde ese momento, el catálogo de títulos del Círculo Militar -sello de referencia de las Fuerzas Armadas- contó con una nueva área, dedicada a la guerra contrarrevolucionaria. La editorial explicó su cometido de "actualizar y acrecentar la aptitud profesional de los oficiales de nuestro ejército, en relación con las nuevas exigencias que les impone la entrada en escena de la guerra subversiva"32. Así es, desde 1962, tras la publicación de Guerra Revolucionaria Comunista, la literatura

\footnotetext{
${ }^{27}$ Para cada una de ellas, se pueden consultar: COMBLIN, Joseph. Le pouvoir militaire en Amerique Latine: l'idologie de la securite nationale. París: Delarge, 1977; y ROBIN, Marie. Escuadrones de la muerte: la escuela francesa. Buenos Aires: Sudamericana, 2004.

${ }^{28}$ LANUSSE, Agustín. Palabras que pronunciara el señor coronel D. Alejandro Agustín Lanusse, en la ceremonia de egreso de oficiales de Estado Mayor, el día 17/12/60. Revista de la Escuela Superior de Guerra. 1960, n. 339, p. 680.

${ }^{29}$ Declaraciones del militar argentino Alcides López Aufranc, recogidas en el documental de ROBIN, Marie. Escadrons De La Mort: L'Ecole Française [filme-documental]. Francia, 2003.

${ }^{30}$ El Curso fue el primero de su tipo en realizarse dentro del continente americano. Contó con la asistencia de jefes militares de Argentina, Bolivia, Colombia, Chile, Ecuador, Estados Unidos, Guatemala, Honduras, México, Panamá, Paraguay, Perú, Uruguay y Venezuela. Para un estudio del mismo, puede consultarse: CAÑÓN VOIRIN, Julio Lisandro. La guerra revolucionaria en la perspectiva de las FF.AA. argentinas. Naveg@mérica. Revista electrónica editada por la Asociación Española de Americanistas [en línea]. 2012, n. 9. [Fecha de consulta: 19/02/2020]. Disponible en $<$ https://revistas.um.es/navegamerica/article/view/161971>.

31 TÚROLO, Carlos. Legislar contra el comunismo. Clarín. 03/10/61.

32 GRANILLO FERNÁNDEZ, Abraham. Biblioteca del Oficial. Bodas de Oro 1916-1966. Buenos Aires: Círculo Militar, 1966, p. 16.
} 
militar especializada parece conocer un único tópico de interés. Ese primer libro, obra de Osiris Villegas, fijó los postulados de la acción contrarrevolucionaria "una guerra sin cuartel, sin transacción posible, donde todos los métodos de lucha son lícitos y, por eso, resulta muchas veces cruel y antiética" ${ }^{33}$.

Será, el recién mencionado, Osiris Villegas responsable de redactar el discurso pronunciado por el comandante en jefe del Ejército, Juan Carlos Onganía, en la $V$ Conferencia de Ejércitos Americanos (1964) ${ }^{34}$. Dicho discurso, significó la asunción formal, por parte de las Fuerzas Armadas, de la reorientación castrense hacia un nuevo tipo de guerra. Algo que, para 1969, ratificaría el, entonces, comandante en jefe del Ejército, Alejandro Agustín Lanusse: "la guerra ha cambiado de forma [...], ya que la existencia palpable de fronteras ideológicas internas coloca al enemigo también dentro de las naciones mismas,"35. Esto significó una ruptura en dos sentidos: por una parte, las fronteras pasaban a ser ideológicas; por otra, la definición del enemigo se enunciaba hacia el interior de la propia sociedad.

Aunque, lo anterior se inscribe en un clima de época, marcado por la Guerra Fría, ello no explica ni cómo ni por qué se actuó en unos campos de batalla imaginarios -con víctimas reales, de carne y hueso- contra una entidad mítica, un enemigo terrorífico: la subversión de inspiración comunista. Es la fuerza beligerante de la concepción castrense, la que permite entenderlo: "esta guerra en la que el mundo ya se encuentra empeñado, frecuentemente no presenta frentes ni operaciones formales; no comienza en las fronteras, ni se inicia con declaración alguna; tampoco aparece fatalmente como fisonomía comunista definida, sino como cosa de lobos con piel de corderos. Como las enfermedades degenerativas, exige un diagnóstico precoz y la intervención quirúrgica apartada de las técnicas militares tradicionales" ${ }^{\prime 36}$.

Las Fuerzas Armadas que, desde el golpe de Estado de 1930, intervenían activamente en la vida política del país, consideraron que los mecanismos constitucionales y jurídicos eran ineficaces para la nueva situación. Los informes militares insistían y presionaban por introducir cambios en la infraestructura represiva $^{37}$. Así, tras el golpe de Estado de 1962, los aparatos coercitivos sufrieron

\footnotetext{
${ }^{33}$ VILLEGAS, Osiris. Guerra Revolucionaria Comunista. Buenos Aires: Círculo Militar, 1962, p. 66.

${ }^{34}$ Las conferencias no están previstas, ni reglamentadas en ningún tratado o acuerdo internacional. Establecen una relación directa entre los comandantes generales de los Ejércitos, sin intervención de los ministerios de Relaciones Exteriores. La primera de las conferencias se realizó en la zona del Canal de Panamá, en 1960, por invitación del mayor general Bogart, comandante de las Fuerzas del Ejército del Comando Sur de los Estados Unidos. Participaron de la misma y en las sucesivas reuniones: Argentina, Ecuador, Panamá, Bolivia, El Salvador, Paraguay, Brasil, Estados Unidos, Chile, Guatemala, Uruguay, Colombia, Honduras, Venezuela, Costa Rica, Nicaragua y Perú.

35 VIAGGIO, Julio. La doctrina de la seguridad nacional. Buenos Aires: Derechos del hombre, 1985, p. 73.

${ }^{36}$ SÁNCHEZ DE BUSTAMANTE, Tomás. La Guerra Revolucionaria. Revista de la Escuela Superior de Guerra. 1960, n. 339, p. 609.

${ }^{37}$ Al respecto pueden consultarse distintos estudios, publicados por los propios militares en la Revista de la Escuela Superior de Guerra, particularmente: MONTES, Miguel Ángel. Las guerras del futuro en la era atómica, guerra nuclear, guerra nuclear restringida, guerra convencional, guerra social revolucionaria. Revista de la Escuela Superior de Guerra. 1957, n. 326, pp. 374-396; RUÍZ MORENO, Isidoro. Problemas actuales de la política internacional. Revista de la Escuela Superior de Guerra.
} 
una profunda readecuación. Bajo la fundamentación de que "las nuevas formas de acción subversivas desarrolladas por el enemigo"38 requerían un aumento de los dispositivos de control, se introdujeron modificaciones en la Secretaría de Informaciones del Estado. Esta pasó a tener una significativa injerencia en la gobernabilidad, ya que, desde ese momento, debía proveer al gobierno de todos los elementos necesarios para atender los asuntos de Seguridad Nacional. Ya no solo era responsable de recoger información y producir inteligencia, ahora, tenía a su cargo la planificación de las políticas de seguridad interior. Sobre todo, debía dirigir y supervisar las medidas estatales contra el comunismo.

Por otra parte, y en un símil con la fantasía orwelliana de 1984, los servicios de inteligencia actuaron como "una Policía del Pensamiento" que vigilaron a todos. Mientras realizan operaciones conjuntas con las Fuerzas Armadas, para el registro y decomiso de material marxista ${ }^{39}$, investigan y catalogan a todas las instituciones y personas que, real o presuntamente, estén relacionadas con el comunismo. La consideración de comunista no respondía a un criterio restrictivo, pues era el propio Estado, a través de los servicios de inteligencia, quien determinaban el carácter de tal. Otra innovación, en la estructura de inteligencia, fueron los departamentos de acción psicológica. Sus campañas, utilizando los más diversos medios -cine, radio, televisión, prensa gráfica-, se orientaron a conformar una sensibilidad contra lo comunista y los comunistas. La sustancia y el impacto de sus acciones es difícilmente conmensurable, pero, sin duda, contribuyeron a instalar la narrativa de una situación de guerra y a identificar una nueva categoría de enemigo: el subversivo.

De esta manera, el aparato militar y de inteligencia estuvo empeñado en la construcción de una otredad negativizada: la subversión. Contra ella, desde el menosprecio de su condición humana, se organizó un aparato coercitivo para desarraigarla del cuerpo social. El espacio territorial argentino, subordinado al proceso de zonificación de guerra interna, fue reconfigurado para identificar, controlar y reprimir a todos aquellos que, desde las esferas del poder, se señaló como subversivos. Siguiendo la experiencia francesa en Argelia, mediante una directiva militar de 1963, Argentina fue dividida en cinco zonas de seguridad que, a su vez, fueron divididas en subzonas y áreas. La puesta a punto de las condiciones de vigilancia se completó con el sistema francés, también aplicado en Argelia, del

1957, n. 327, pp. 457-482; GIOVANELLI, Jorge. Los grandes problemas de la defensa nacional. Revista de la Escuela Superior de Guerra. 1960, n. 337, pp. 135-146; GRAND D'ESNON, Henri. Guerra subversiva. Revista de la Escuela Superior de Guerra. 1960, n. 338, pp. 339-363; MOM, Manrique Miguel. Guerra Revolucionaria Causas-Proceso-Desarrollo. Revista de la Escuela Superior de Guerra. 1959, n. 334, pp. 489-515; CORDINI, Juan Carlos. Anexo Reservado. La situación de la República Argentina en el bloque de naciones democráticas en 1959. Revista de la Escuela Superior de Guerra. 1959, n. 333, pp. 405-420; LABORDA IBARRA, Matías y ASTIGUETA, José Manuel. Consideraciones en torno a una ley de Defensa Nacional. Revista de la Escuela Superior de Guerra. 1962, n. 347, pp. 385-399.

${ }^{38}$ Decreto-Ley № 778/1963, de 30 de enero. Seguridad de la Nación. Boletín Oficial de la República Argentina, 19 de diciembre de 1983, núm. 20045, p. 1.

39 Por ejemplo: la llamada Operación Prensa, que se desarrolló entre 1960 y 1961. La operación se realizó de forma conjunta con la Policía Federal, Gendarmería y Prefectura. Abarcó todo el territorio de Argentina. Para el cumplimiento de la operación, se creó en el ámbito de la Presidencia de la Nación, la Comisión para la Investigación de Actividades Comunistas. 
"quadrillage" -división cuadricular de las ciudades-.

La nueva territorialidad adquirió su forma definitiva en mayo 1976, cuando, a casi dos meses del golpe de Estado, la dictadura del PRN decidió reestructurar las jurisdicciones para la "intensificación gradual y acelerada de la acción contrasubversiva" ${ }^{\text {" }}$. En otras palabras, el secuestro y exterminio de los grupos, reducidos a una otredad negativizada por el aparato militar y de inteligencia, debía ser un proceso acelerado. En ese sentido, las estrategias del terrorismo de Estado se centraron, por una parte, en la centralización e incremento de las actividades de inteligencia; por otra, en el dominio del espacio geográfico ${ }^{41}$. De esta manera las zonas, las subzonas y las áreas constituyeron la matriz en el tramado del complejo represivo estatal, pero que, a su vez, permite distinguir las variables regionales, e incluso locales, de las distintas partes que lo componen. Pues, si bien el significante del terrorismo de Estado no varió, la intensidad del terror sí. En ese sentido, las áreas se distinguen y adquieren particular relevancia, ya que eran los espacios operacionales concretos, donde estaban las unidades de inteligencia, actuaban sistemáticamente los grupos de tareas, y se situaban los centros de exterminio.

\section{Del terrorismo de Estado y su durante}

El golpe de Estado del 24 de marzo de 1976 fue un golpe muy distinto a los anteriores. Por primera vez, las tres Fuerzas Armadas -Ejército, Marina y Fuerza Aérea- actuaron de manera conjunta y de forma coordinada. No solo se repartieron el poder por partes iguales, sino también la participación en la represión. Una junta, compuesta por los comandantes de las tres armas, asumió el gobierno del PRN: la Junta de Comandantes Generales. La Junta se instituyó como poder constituyente, disolvió el Congreso, otorgó facultades legislativas al Poder Ejecutivo, hizo desaparecer la división de poderes, suprimió los derechos civiles, las libertades públicas, anuló las garantías constitucionales y, por encima de todo, colocó el Acta y los Objetivos Básicos del PRN.

El Acta otorgó amplias facultades a la Junta. Ente ellas, el comando supremo de todas las Fuerzas de Seguridad con el fin expreso de aniquilar a la llamada subversión ${ }^{42}$. Tras poco más de un año en el poder, las Fuerzas Armadas reconocían que "la asunción del Gobierno Nacional por parte de las FFAA el 24 Mar 76, permitió concebir una ENC [Estrategia Nacional Contrasubversiva] integral, coherente y cuya aplicación fuese conducida desde el más alto nivel del Estado. Esto significó un cambio substancial de las condiciones en que se llevaba a cabo la LCS [Lucha Contra la Subversión], haciendo posible aumentar considerablemente su eficacia" ${ }^{\prime 3}$.

${ }^{40}$ Comandante General del Ejército. Orden parcial 405/76 (Reestructuración de jurisdicciones y adecuación orgánica para intensificar las operaciones contra la subversión), de 21 de mayo de 1976 [en línea]. [Fecha de consulta: 19/02/2019]. Disponible en <http://www.desaparecidos.org/nuncamas/web/document/militar/40576.htm>.

41 Ibídem.

42 "Acta fijando el propósito y los objetivos básicos para el PRN". En: Junta Militar. Documentos Básicos y Bases Políticas de las Fuerzas Armadas para el Proceso de Reorganización Nacional. Buenos Aires: Imprenta del Congreso de la Nación, 1980, pp. 3-27.

${ }^{43}$ Comandante en Jefe del Ejército. Directiva del Comandante en Jefe de Ejército № 504/77. 
Esa reorganización general del régimen político y del Estado, en la que los aparatos represivos expresan una mayor presencia, fue conducida desde los más altos niveles ${ }^{44}$. La represión, en todo el país, consistió en un procedimiento igual y minuciosamente calculado. El establecimiento y control de setecientos sesenta y dos campos de concentración, los secuestros masivos y planificados, solo fueron posibles por el funcionamiento vertical y homogéneo de la Junta. Como así también, por la homogeneidad de los intereses de todos los organismos, con funciones o actividades especializadas, y su convergencia a los "objetivos básicos para el PRN" 45 , que determinaron las fronteras de la rivalidad dentro de la burocracia. Aunque, la zonificación del territorio muestra que la orientación estratégica, en la conducción del proceso represivo, fue delegada sobre los cuadros intermedios de las Fuerzas Armadas. Así, la Junta, se aseguró el cumplimiento de las órdenes, con una cierta autonomía de los jefes de cada área, responsables de las tomas de decisiones de carácter coyuntural sobre la aplicación del terror ${ }^{46}$.

Lo anterior, no es otra cosa más que la evidencia de que el Estado terrorista tuvo diferentes ramas. Bajo cada una de ellas existió una estructura jerárquica que, a su vez, tenía dependencias especializadas que se ocuparon de tareas específicas, organizadas para tratar aspectos particulares, unidades territoriales y operacionales. En la base, se encontraban las, ya mencionadas, áreas, espacios de represión reducidos -urbanos, suburbanos, rurales-, con su propia jurisdicción y articuladas en las Unidades de Comando, responsables de los Centros de Alta Intensidad Represiva. Por encima de ellas estaban las Unidades de Inteligencia, a cargo de los Centros de Exterminio. En la cima, estas ramas del Estado terrorista se complementaron entre sí, para alcanzar su objetivo "erradicar la subversión"

En cuanto a los Centros de Alta Intensidad Represiva, son sitios donde los secuestrados permanecieron por períodos cortos o discontinuos, para, posteriormente, ser trasladados a centros de exterminio, derivados al sistema penal o puestos en libertad vigilada. Por su parte, los Centros de Exterminio, donde los secuestrados estuvieron por períodos prolongados, son ramas del Estado específicas para destruir, para matar de una manera singular: la desaparición del secuestrado. En unos y otros, actuaban los agentes de castigo, los perpetradores del terror: los torturadores. Estos poseían saberes específicos que, a través de tormentos, disociaban del mundo social, de sí mismos, del tiempo y del espacio a los secuestrados.

(Continuación de la ofensiva contra la subversión durante el período 1977/78) [en línea]. [Fecha de consulta: 19/02/2019]. Disponible $<$ http://www.desaparecidos.org/nuncamas/web/document/militar/50477.htm>.

44 Véanse las tres fases Preparación; Ejecución; Consoldiación, estipuladas en: Junta de Comandantes Generales. Plan del Ejército (Contribuyente al Plan de Seguridad Nacional) [en línea]. [Fecha de consulta: 19/02/2019]. Feb. 1976. Disponible en $<$ http://www.desaparecidos.org/nuncamas/web/document/document.htm>.

${ }^{45}$ Junta Militar. Acta fijando el propósito..., Op. cit., p. 8.

${ }^{46}$ Junta de Comandantes Generales. Plan del Ejército..., Op. cit.

47 Junta Militar. Acta fijando el propósito..., Op. cit., p. 7. 
En la provincia de Entre Ríos, existieron, al menos, quince campos de concentración $^{48}$. En tres de ellos, Regimiento de Caballería Blindada de Concordia, La Casita y la Unidad Penal oㅜ 6 -cárcel de mujeres-, en condiciones infrahumanas, sin camas ni abrigos, con alimentación deficiente y sin tener permitido higienizarse o ir al baño, estuvieron cautivas: Violeta, Rosa, Azul y Celeste, las cuatro mujeres que nos han brindado su testimonio para construir este trabajo. Algunas de ellas participaron como querellantes en la denominada megacausa Área Paraná -con sentencia, $23 / 12 / 15-{ }^{49}$. Antes de seguir avanzando, nos parece importante señalar que, tanto en las entrevistas, como en los juicios -en el caso de aquellas que participaron-, sus historias políticas previas al golpe aparecían muy vívidamente. Es decir, se hacía presente la vitalidad de su militancia.

Las causas judiciales demostraron la existencia de secuestros, torturas, asesinatos, desapariciones, entierros clandestinos, robos de bebés recién nacidos, sustitución de identidades de menores, cesantías laborales y persecuciones ideológicas. En Entre Ríos, todo ello estuvo a cargo de, al menos, tres grupos de tareas integrados por alrededor de cincuenta personas pertenecientes al Ejército, la Policía Federal, la Policía de Entre Ríos y el Servicio Penitenciario de Entre Ríos, bajo dependencia jerárquica directa de la Comandancia del II Cuerpo de Ejército, a través de la II Brigada de Caballería Blindada. Los grupos se desempeñaron, territorialmente, sobre las ciudades de Paraná, Concordia, Concepción del Uruguay, Diamante y Gualeguaychú, utilizando propiedades del ejército argentino, la policía, el servicio penitenciario, tomando además propiedades privadas, para la ejecución de las tareas de secuestros y torturas.

Violeta y Rosa fueron secuestras en el mismo operativo. En su casa fueron rápidamente reducidas, golpeadas, encapuchadas y esposadas:

"Una patota irrumpió de noche en la casa que compartíamos -cuenta Violeta-. Los integrantes del grupo de tareas nos golpearon, nos encapucharon y nos llevaron a las dos. Ella siempre fue flaquita, y yo siempre fui robustona, me la encajaron atrás en el Falcón, en el traslado, la encajaron en el piso a ella y a mi encima y nos ponen máquinas de escribir encima para aplastarnos, y yo trataba de acomodarme para no aplastarla. Siempre estuvimos esposadas ${ }^{50}$.

El secuestro marcó el ingreso a un universo de vulnerabilización extrema. En primer lugar, por la forma en la que se producía el secuestro, por agentes del Estado, que no se identificaban. En segundo lugar, porque las secuestradas y sus familiares desconocían el lugar de destino. En tercer lugar, porque los Habeas

\footnotetext{
${ }^{48}$ Regimiento II de Comunicaciones de Paraná, Base Aérea de Paraná, La Casita, La Escuelita, Aero Club Gualeguaychú, Unidad Militar de Gualeguaychú, Regimiento de Caballería Blindada de Concordia, Unidad Penal ํo 1, Unidad Penal ํo 6, Unidad Penitenciara ํo 2, Comisaría "El Brete", Delegación Paraná de la Policía Federal, Dirección de Investigaciones de la Policía Provincial, Policía de la Provincia de Entre Ríos, Delegación Concepción del Uruguay de la Policía Federal.

${ }^{49}$ En la megacausa Área Paraná fueron condenados cuatro militares (Jorge Humberto Appiani, José Anselmo Appelhans, Alberto Rivas y Oscar Ramón Obaid), un policía federal (Cosme Ignacio Marino Demonte), una agente penitenciaria (Rosa Susana Bidinost) y un médico (Hugo Mario Moyano). Por otra parte, de esta causa se desprenden otras cuatro, conocidas como: Área Paraná II, La escuelita, Comisaría El Brete, Capellino.

${ }^{50}$ Entrevista no 1. Violeta.
} 
Corpus, presentados en su favor, eran contestados negativamente. Finalmente, porque en el campo de concentración eran clasificadas y se les cambiaba el nombre por un número; se las desposeía de sus ropas, hasta quedar desnudas.

Los golpes y los insultos recibidos durante el secuestro y el traslado al primer campo que tuvieron como destino, eran la antesala al proceso de tormentos y torturas. La espera se aletarga, la incertidumbre crece, y muy cerca de ellas los desgarradores gritos de otros secuestrados: "escuchar los gritos de un compañero... eso sí que era durísimo"

\begin{abstract}
"Cuando estamos en los jardines del sitio donde nos trasladan [La Casita], estaban torturando a mucha gente; ahí, mientras esperamos para entrar en la sala de torturas, me violan los que me estaban custodiando, tres tipos me violan. El que comanda la patota, me desnuda y me empieza a picanear y me violan cuatro personas. Siempre tabicadas [encapuchadas], nos torturaban; en ocasiones nos quitaban las esposas para torturarnos por separado. Durante una semana mantienen la misma rutina: nos picanean y nos interrogan; uno de esos días es que me viola el jefe de policía. Después de esa semana nos trasladan a la Unidad Penal no 6 -cárcel de mujeres-, y ahí quedo detenida durante ocho meses; a ella la tuvieron más tiempo" ${ }^{2}$.
\end{abstract}

Por la misma sala de tormentos pasó Celeste, militante política de otra organización y secuestrada unos meses después que Rosa y Violeta. Los detalles son semejantes, una cama metálica, una picana eléctrica, con su regulador de voltaje y algunas sillas. Celeste, como antes Rosa y Violeta, fue esposada a la cama y los torturadores se sucedían en el rol de interrogador y torturador. Celeste cuenta la primera noche de su secuestro en La Casita:

\begin{abstract}
"Me llevan hasta una pequeña habitación donde me esposaron de pies y manos al elástico de una cama con flejes de metal y toda una patota se dedica a torturarme, primero me pasan corriente eléctrica, y el jefe me dice: 'Ahora vas a ver, hija de puta, vas a saber lo que es Enriqueta', me dijo refiriéndose a la picana, para luego agregar: 'Qué olor que tenés, ¿por qué no te bañaste, sucia?’"53.
\end{abstract}

Ella contestó que había sido abusada hacía unos instantes y su respuesta generó "un silencio en el ambiente", lo que la llevó a pensar que el jefe "no sabía que había sido violada" o que "la violación no debe haber estado autorizada por él". Tras la tortura, cuando la patota se retiró, se presentó un soldado a tratar de consolarla, que le ofreció un mate y le preguntó "si podían tener relaciones porque la boca le hacía recordar a su novia" ${ }^{2}$. Todo lo que a los agentes de castigo se les podía ocurrir era plausible de ser realizado.

Tras el paso por los Centros de Alta Intensidad Represiva, fueron trasladadas a la Unidad Penal no 6. Sin embargo, no era infrecuente que volvieran a los Centros y que, desde estos, volvieran a la cárcel. En cualquier caso, lo que se mantuvo fue el

\footnotetext{
${ }^{51}$ Entrevista no 4. Azul.

${ }^{52}$ Entrevista no 1. Violeta.

53 Entrevista no 3. Celeste.

${ }^{54}$ Entrevista no 3. Celeste.
} 
régimen de tormentos. Azul cuenta cómo una noche fue retirada de su celda, en la Unidad Penitenciara no 6, y trasladada a:

"Una piecita con una cama y un baño. Había también una máquina de escribir donde una persona confeccionaba las actas con las declaraciones que les arrancaban a los detenidos bajo tortura. 'Te acuso, gorda, de provocativa' -le dijo uno de los interrogadores, cuando la vio llegar vestida con una camiseta traslucida-" ${ }^{-55}$.

Rosa, por su parte, detalla como todas las noches las llevaban de su celda a la Unidad Familiar: "y ahí nos torturaban"56. Es decir, el paso al sistema penal no garantizó, ni mucho menos, el fin de la tortura. Tanto es así que la exdirectora de la Unidad Penal $n^{\circ} 6$ fue condenada por:

"Sus omisiones sobre el conocimiento que tenía acerca de las circunstancias en que se ejecutaban las detenciones y los traslados de las internas con evidentes signos a su regreso de haber sido torturadas, la colocan en el lugar de colaboradora relevante de quienes de propia mano consumaban los tormentos a raíz de los cuales vertieron declaraciones autoincriminatorias y datos sobre sus relaciones vinculadas a la actividad política"s7.

De esas declaraciones autoincriminatorias, nos da cuenta Rosa que fue sometida a una parodia de juicio ante tribunales militares. En este, se utilizaron como pruebas de cargo, actas de supuestas declaraciones en contra de sí misma, que fue obligada a firmar bajo tormentos, vejaciones y amenazas. Posteriormente, fue protagonista de un simulacro de fusilamiento ${ }^{58}$. La crueldad creativa del exceso, tuvo capacidad de elaborar narrativas que reforzaban los miedos básicos. "No puedo estar en lugares cerrados -dice Violeta-. Por ejemplo, voy al baño y dejo la puerta abierta, siempre tengo la puerta abierta; no tolero estar encerrada. Creo, que tiene que ver con el tema de la capucha, la sensación de ahogo y la violación" ${ }^{\prime 5}$.

Sus cuerpos blanco muerte, desnudos, atados con alambres a un elástico que alguna vez fue parte de una cama, yacían deseando morir, cuando les aplicaban la picana en los genitales. Gritaban hasta morir, pensaban que estaban muertas, pero no, se desmayaban, perdían la conciencia y no recuerdan más: "creí que me mataba. Era muy dura la tortura y muchas veces deseábamos morirnos para que se acabara" quitar la vida o darla, y trasmutar la subjetividad y los cuerpos, los hacía erigirse como señores de la vida y de la muerte, pero también en alquimistas. Rosa, Violeta, Azul, Celeste, cuentan cómo sufrieron un proceso de cambios en sus cuerpos, en sus psiquismos, en sus sentimientos. Lenta o aceleradamente, van perdiendo la

\footnotetext{
${ }^{55}$ Entrevista ํㅜ 4. Azul.

${ }^{56}$ Entrevista ํㅜㅇ. Rosa.

57 Juzgado Federal № 1, Paraná. Expte. FPA № 13007824/2003/CA31, caratulado: "Appelhans José Anselmo (d); Bidinost Rosa Susana (d); Moyano Mario Hugo (d); Appiani Jorge Humberto (d) Sobre inf. 144 bis en circ. art. 142 inc. 1, 2, 3, 5 privacion ilegal de la libertad agravada (art. 142 inc. 1) imposición de tortura (art. 144 ter inc. 1)".

${ }_{58}$ Entrevista no 2. Rosa.

${ }^{59}$ Entrevista 우 1 . Violeta.

${ }^{60}$ Entrevista no 2. Rosa.
} 
identidad, la percepción se distorsiona, la movilidad se obtura, las funciones básicas del organismo se infantilizan, y en varios casos, si la muerte no llegaba en auxilio, el arrasamiento corpóreo era total. Esa era la obra de un alquimista, de un agente de castigo. Matar, dejar vivir, atormentar para transmutar.

De entre las huellas que el terrorismo de Estado les dejó, las violaciones, abusos y agresiones sexuales que sufrieron adquieren una significancia singular. "Toda violación implica mucha culpa también y, aparte, mucha vergüenza. Es una de las torturas más denigrantes para una mujer, creo que tiene que ver con eso, el asumir que vos fuiste violada es terrible"61. La violencia sexual contra las mujeres, durante el terrorismo de Estado, pone en evidencia complejos patrones de victimización y sufrimiento. Según Martínez, la violación, dentro de un esquema de poder masculinizado, fue una manera "de poner a la mujer en su lugar, acallar su rebeldía y mostrarle el lugar que ocupaba, su feminidad esencial y su rol inalterable" semejante, afirma Villegas, "La finalidad fue someter al poder patriarcal manifestado en un orden sexual y político, imprimiendo identidades femeninas en esos cuerpos y castigarlos por haberse apartado de los roles asignados por las relaciones binarias

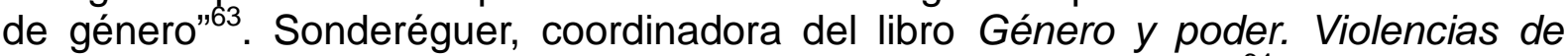
género en contextos de represión política y conflictos armados ${ }^{64}$, indica que el castigo de la dictadura hacia las mujeres era no solo por subversivas, sino también por ir en contra de lo que la sociedad patriarcal esperaba de ellas por ser mujeres.

No fue, la época del terrorismo de Estado, la primera etapa histórica en la que la violencia sexual se practicó masiva y sistemáticamente contra las mujeres, y todo parece indicar que tampoco será la última. No obstante, durante el terrorismo de Estado, las violaciones y agresiones sexuales adquieren la particularidad de ser empleadas como método de tortura; y en ese mismo marco, deberían ser entendidas como crímenes contra la humanidad. Sin embargo, en el ámbito del derecho internacional de los Derechos Humanos ninguno de los dos instrumentos internacionales que prohíben la tortura, Convención contra la Tortura y Otros Tratos o Penas Crueles, Inhumanos o Degradantes (ONU, 1984), Convención Interamericana para prevenir y sancionar la tortura (OEA, 1987), incluyen a la violencia sexual como un medio de tortura.

Dice Foucault, refiriéndose al verdugo medieval, que la tortura es "una verdadera lucha física cuyas reglas, por supuesto, aunque no amañadas, eran perfectamente desiguales y sin ninguna reciprocidad: una lucha física para saber si el sospechoso iba a aguantar o no"65. Así entendidas, las prácticas del terrorismo de Estado en la sala de tormentos son un hecho político. Desde esta perspectiva, podemos

\footnotetext{
${ }^{61}$ Entrevista oㅜ 1. Violeta.

62 MARTíNEZ, Paola. Cuerpos y subjetividades en disputa: Experiencias femeninas en los centros clandestinos de detención en Argentina (1976-1983). L'Ordinaire des Amériques [en línea]. 2017, n. 222. [Fecha de consulta: 20/02/2019]. Disponible en <http://journals.openedition.org/orda/3491>.

${ }_{63}$ VILLEGAS, María. La violencia contra las mujeres en el marco del terrorismo de Estado en Argentina. Revista Derechos en Acción. 2018, vol. 9, n. 9, p. 257.

${ }^{64}$ SÓNDEREGUER, María. Género y poder. Violencias de género en contextos de represión política y conflictos armados. Bernal: Universidad Nacional de Quilmes, 2012.

${ }^{65}$ FOUCAULT, Michel. El poder psiquiátrico. Buenos Aires: Fondo de Cultura Económica, 2007, p. 265.
} 
entenderlas como un instrumento de control, o una "táctica política" 66 que domina el cuerpo para doblegar el alma. En ese escenario, las mujeres, el cuerpo de las mujeres, se convirtió en territorio de quienes tienen el poder. Las violaciones, agresiones y abusos, como una invasión física de naturaleza sexual se practicaron con el consentimiento o la aquiescencia de los más altos mandos de las Fuerzas Armadas. Es decir, una modalidad específica de violencia, cometida por agentes estatales y de conformidad con la política de Estado.

\section{Notas finales}

El conocimiento social, la creación de saberes, está absolutamente estructurado por dispositivos políticos. No hay conocimiento neutral. No solo no hay conocimiento neutral, sino que la neutralidad del conocimiento es, en sí misma, una posición política. La producción de conocimiento acerca de la historia reciente tiene efectos sobre el conjunto de la sociedad. En primer lugar, porque el análisis mismo de los hechos debería permitir comprender los procesos que han resultado en nuestro presente y las tendencias que se desarrollan en él. En segundo lugar, y como consecuencia de lo anterior, porque según sean los conocimientos que se difundan a la sociedad será la conciencia que de su propio pasado y de su presente esta podrá tomar.

Acercarse al terrorismo de Estado es acercarse al conocimiento de una nueva faceta del colapso de la humanidad en el siglo XX -como antes lo fueron el genocidio contra los armenios, el genocidio nazi, Nagasaki e Hiroshima-. Allí sucedió algo con lo que nunca nos podremos reconciliar. El terrorismo de Estado ya sucedió, pero el fenómeno, en tanto proceso, no se cerró. Piénsese sino en los que, aún hoy, siguen buscando y rebuscando en fosas, donde la furia de un poder aniquilador quiso condenar a los desaparecidos. ¿Cómo explicar el terrorismo de Estado? El intentar explicarlo, el hecho de comprender los motivos, las causas de las desapariciones planificadas ¿podría suponer quitarle magnitud a la atrocidad? Creemos que no. Desde ese lugar, hemos pensado este trabajo.

La primera premisa, la cual no debe olvidarse, es que las raíces han de buscarse en los perpetradores, no en las víctimas. Los únicos responsables son los que aplicaron la furia exterminadora. El científico social, con su labor, debe contribuir a evitar que ello vuelva a ocurrir, o al menos permitir estar alertas cuando pueda sobrevenir. Trabajar para la no repetición de lo ocurrido, implica, en nuestra actualidad, centrarse en el aspecto subjetivo. Porque la posibilidad de transformar los presupuestos objetivos, es decir, sociales y políticos, en los que el terrorismo de Estado encontró sus condiciones de posibilidad, es hoy claramente limitada. En aquel momento, como señaló Marcuse, la defensa del sistema capitalista necesitó de la contrarrevolución: "se producen masacres al por mayor con cualquiera que se llame 'comunista' o que esté en rebeldía contra los gobiernos subordinados a los países imperialistas" $"$.

\footnotetext{
${ }^{66}$ FOUCAULT, Michel. Vigilar y castigar. México: Siglo XXI, 1987, p. 30.

${ }^{67}$ MARCUSE, Herbert. Contrarrevolución y revuelta. México: Joaquín Mortiz, 1973, p. 11.
} 
Si nos situamos en esa perspectiva, podemos decir que, tal como mencionáramos en las páginas introductorias, uno de los ejes que dan inteligibilidad al terrorismo de Estado está en la capacidad performativa de los discursos que niegan la condición de seres humanos a las potenciales víctimas. En otras palabras, cómo vieron y conocieron a los grupos eliminables, cómo se configuró la relación con el otro -subversivo-. La configuración de los grupos reducidos a una otredad negativizada partió de su no reconocimiento social, salvo en su rol admitido y socialmente construido de agresor. Las relaciones, con ese otro, fueron desplazadas al de una guerra ideológica. Al mismo tiempo, los conflictos sociales fueron situados en el marco de una confrontación bélica. Como señalamos, la construcción semántica del enemigo comenzó hacia finales de los años cincuenta, fijando los lineamientos de una persecución, que fundamentó la reorganización de la estructura de seguridad. Se delineaba el perfil del enemigo y se introducían modificaciones al marco legal, para combatir a los sujetos percibidos como una amenaza. La existencia de una guerra interna, buscando la eliminación de los subversivos, se convirtió en política de Estado.

A pesar del ocultamiento, con el cual se instaló el aparato coercitivo extraoficial, el propio Videla, durante el PRN, debió dar cuenta de este: "toda guerra deja una secuela de muertos, desaparecidos, prisioneros"68. Pero, esa pretensión de establecer la guerra como lógica de comprensión del proceso, no permitía ver la visión que pudieran haber tenido los "muertos, desaparecidos, prisioneros". Es más, omitía cuidadosamente referirse a esos acontecimientos, de qué tipo fueron, y por intervenir en ellos seres humanos, a quiénes beneficiaron o perjudicaron.

El campo de concentración es un espacio autónomo, ocupa un espacio aislado del resto del territorio. Es, además, un espacio acumulativo, se acumulan personas para ser torturadas. Así como el ejército colonial francés uso la tortura en Argelia, en Argentina fue utilizada en los campos de concentración. En ambos casos, la tortura tenía una finalidad de inteligencia: obtener información. Pero, además, en la tortura hay una racionalidad "sobre todo si es científica, es utilizada también en cuanto a determinar daños permanentes en la capacidad operativa del torturado"69. Para la tortura es esencial el dolor, que el ser humano sufra. Justamente lo contrario de lo que funda la ética de los Derechos Humanos.

Desde hace varios años, se han producido intensos debates que cuestionan la validez universal del androcentrismo y del modelo del hombre occidental. Se ha apuntado a la necesidad de analizar el tema de los Derechos Humanos en relación con la democratización de las relaciones de género ${ }^{70}$. Sonderéguer señala que el tratamiento de la violencia específica sobre las mujeres en la última dictadura "pone en revisión el orden sociocultural" y no solo el del contexto del terrorismo de Estado. Al respecto también apunta que la impunidad con la que se ejecutó la violencia sexual durante el terrorismo de Estado "pone de manifiesto todos los prejuicios

\footnotetext{
${ }^{68}$ VIDELA, Jorge Rafael. Cara a cara Videla con los periodistas. Revista Gente. 20/12/79, n. 752.

69 JERVIS, Giovanni. La tecnología della tortura. Sapere. 1974, n. 777, p. 30.

${ }^{70}$ Véase, RICO, Nieves. Violencia de género: un problema de Derechos Humanos. Mujer y desarrollo. 1996, n. 16, p. 7.
} 
sexistas que subyacen aún hoy en la valoración de los delitos sexuales" 71 . Porque toda agresión contra las mujeres presenta rasgos que permite identificarla como violencia de género. En síntesis, que anida en el carácter asimétrico de las relaciones hombre-mujer, perpetuando la desvalorización de lo femenino y su subordinación a lo masculino. El hecho de ser mujer es, en sí mismo, un factor de riesgo. Es un imperativo categórico modificar el patrón que identifica a las mujeres con posiciones de inferioridad o subordinación.

\section{Bibliografía}

AGAMBEN, Giorgio. Estado de Excepción, Homo sacer, II, I. Buenos Aires: Adriana Hidalgo, 2004.

ARENDT, Hannah. Los orígenes del totalitarismo. Buenos Aires: Taurus, 1998.

AUSTIN, John. How to Do Things with words. Cambridge: Harvard University Press, 1975.

AZNAREZ, Juan Jesús. Denegado el ascenso a dos marinos argentinos. El País. 28/10/94.

BENJAMIN, Walter. Tesis sobre la historia y otros fragmentos. México: UA, 2008.

CALVEIRO, Pilar. La experiencia concentracionaria. En: YANKELEVICH, Pablo (comp.). Argentina, 1976: estudios en torno al golpe de Estado. Buenos Aires: Fondo de Cultura Económica, 2008.

CAÑÓN VOIRIN, Julio Lisandro. El Estado terrorista en América. Una historización sobre su configuración. Dossier Violencia estatal, persecutoria, ideologías, terrorismo de estado y genocidio. Confluenze, Rivista di studi iberoamericani. 2018, vol. X, n. 2, pp. 4-33.

CAÑÓN VOIRIN, Julio Lisandro. La guerra revolucionaria en la perspectiva de las FF.AA. argentinas. Naveg@mérica. Revista electrónica editada por la Asociación Española de Americanistas [en línea]. 2012, n. 9. [Fecha de consulta: 19/02/2020].

Disponible <https://revistas.um.es/navegamerica/article/view/161971>.

Comandante en Jefe del Ejército. Directiva del Comandante en Jefe de Ejército № 504/77. (Continuación de la ofensiva contra la subversión durante el período 1977/78) [en línea]. [Fecha de consulta: 19/02/2019]. Disponible en $<$ http://www.desaparecidos.org/nuncamas/web/document/militar/50477.htm>.

Comandante General del Ejército. Orden parcial 405/76 (Reestructuración de jurisdicciones y adecuación orgánica para intensificar las operaciones contra la

\footnotetext{
${ }^{71}$ SÓNDEREGUER, María y CORREA, Violeta (comps.). Violencia de género en el terrorismo de Estado: políticas de memoria, justicia y reparación. Cuaderno de trabajo. Bernal: Universidad Nacional de Quilmes, 2010, p. 11.
} 
subversión), de 21 de mayo de 1976 [en línea]. [Fecha de consulta: 19/02/2019]. Disponible $<$ http://www.desaparecidos.org/nuncamas/web/document/militar/40576.htm>.

COMBLIN, Joseph. Le pouvoir militaire en Amerique Latine: l'idologie de la securite nationale. París: Delarge, 1977.

CORDINI, Juan Carlos. Anexo Reservado. La situación de la República Argentina en el bloque de naciones democráticas en 1959. Revista de la Escuela Superior de Guerra. 1959, n. 333, pp. 405-420.

Decreto № 158/1983, de 13 de diciembre. Acciones penales. Sométese a juicio sumario ante el Consejo Superior de las Fuerzas Armadas a los integrantes de la Junta Militar que usurpó el gobierno de la Nación el 24 de marzo de 1976 y a los integrantes de las dos Juntas Militares subsiguientes. Boletín Oficial de la República Argentina, 25 de diciembre de 1983, núm. 25.321.

Decreto № 187/1983, de 15 de diciembre. Comisión Nacional sobre la Desaparición de Personas. Boletín Oficial de la República Argentina, 19 de diciembre de 1983, núm. 25.325.

Decreto-Ley № 778/1963, de 30 de enero. Seguridad de la Nación. Boletín Oficial de la República Argentina, 19 de diciembre de 1983, núm. 20045.

DUHALDE, Eduardo Luis. El Estado terrorista argentino. Buenos Aires: El Caballito, 1983.

FEIERSTEIN, Daniel. El genocidio como práctica social. Entre el nazismo y la experiencia argentina. Buenos Aires: Fondo de Cultura Económica, 2007.

FOUCAULT, Michel. El poder psiquiátrico. Buenos Aires: Fondo de Cultura Económica, 2007.

FOUCAULT, Michel. Vigilar y castigar. México: Siglo XXI, 1987.

GIOVANELLI, Jorge. Los grandes problemas de la defensa nacional. Revista de la Escuela Superior de Guerra. 1960, n. 337, pp. 135-146.

GRAND D’ESNON, Henri. Guerra subversiva. Revista de la Escuela Superior de Guerra. 1960, n. 338, pp. 339-363.

GRANILLO FERNÁNDEZ, Abraham. Biblioteca del Oficial. Bodas de Oro 1916-1966. Buenos Aires: Círculo Militar, 1966.

JERVIS, Giovanni. La tecnología della tortura. Sapere. 1974, n. 777, pp. 30-36.

Junta de Comandantes Generales. Plan del Ejército (Contribuyente al Plan de Seguridad Nacional) [en línea]. [Fecha de consulta: 19/02/2019]. Feb. 1976. 
Disponible

$<$ http://www.desaparecidos.org/nuncamas/web/document/document.htm>.

Junta Militar. Documento final de la Junta Militar sobre la guerra contra la subversión y el terrorismo. Buenos Aires: La Junta, 1983.

Junta Militar. Documentos Básicos y Bases Políticas de las Fuerzas Armadas para el Proceso de Reorganización Nacional. Buenos Aires: Imprenta del Congreso de la Nación, 1980.

Juzgado Federal № 1, Paraná. Expte. FPA № 13007824/2003/CA31, caratulado: "Appelhans José Anselmo (d); Bidinost Rosa Susana (d); Moyano Mario Hugo (d); Appiani Jorge Humberto (d) Sobre inf. 144 bis en circ. art. 142 inc. 1, 2, 3, 5 privacion ilegal de la libertad agravada (art. 142 inc. 1) imposición de tortura (art. 144 ter inc. 1)".

LA CAPRA, Dominick. Historia y Memoria después de Auschwitz. Buenos Aires: Prometeo, 2008.

LABORDA IBARRA, Matías y ASTIGUETA, José Manuel. Consideraciones en torno a una ley de Defensa Nacional. Revista de la Escuela Superior de Guerra. 1962, n. 347 , pp. 385-399.

LANUSSE, Agustín. Palabras que pronunciara el señor coronel D. Alejandro Agustín Lanusse, en la ceremonia de egreso de oficiales de Estado Mayor, el día 17/12/60. Revista de la Escuela Superior de Guerra. 1960, n. 339, pp. 678-684.

Ley № 22.924/1983, de 23 de marzo. Ley de Pacificación Nacional. Medidas políticas y normativas tendientes a sentar las bases de la definitiva pacificación del país. Boletín Oficial de la República Argentina, 27 de septiembre de 1983, núm. 25266.

Ley № 25.779/2003, de 21 de agosto. Decláranse insalvablemente nulas las Leyes Nros. 23.492 y 25.521. Boletín Oficial de la República Argentina, núm. 30.226.

MARCUSE, Herbert. Contrarrevolución y revuelta. México: Joaquín Mortiz, 1973.

MARTÍNEZ, Paola. Cuerpos y subjetividades en disputa: Experiencias femeninas en los centros clandestinos de detención en Argentina (1976-1983). L'Ordinaire des Amériques [en línea]. 2017, n. 222. [Fecha de consulta: 20/02/2019]. Disponible en <http://journals.openedition.org/orda/3491>.

MOM, Manrique Miguel. Guerra Revolucionaria Causas-Proceso-Desarrollo. Revista de la Escuela Superior de Guerra. 1959, n. 334, pp. 489-515.

MONTES, Miguel Ángel. Las guerras del futuro en la era atómica, guerra nuclear, guerra nuclear restringida, guerra convencional, guerra social revolucionaria. Revista de la Escuela Superior de Guerra. 1957, n. 326, pp. 374-396. 
Naciones Unidas. Protocolo de Estambul. Manual de Investigación y Documentación Efectiva sobre Tortura, Castigos y Tratamientos Crueles, Inhumanos o Degradantes. Ginebra: ONU, 2004.

O’DONELL, Guillermo. El Estado Burocrático Autoritario. Triunfo, derrotas y crisis. Buenos Aires: Editorial de Belgrano, 1972.

Organización de Estados Americanos. Convención Interamericana para Prevenir, Erradicar y Sancionar la Violencia contra la Mujer [en línea]. OEA, 1994. [Fecha de consulta: 19/02/2019]. Disponible en $<$ http://www.oas.org/es/mesecvi/docs/Folleto-BelemdoPara-ES-WEB.pdf>.

Organización de Estados Americanos. Informe sobre la situación de los derechos humanos en Argentina [en línea]. O.E.A., abril 1980. [Fecha de consulta: 19/02/2019]. Disponible en $<$ http://www.cidh.oas.org/countryrep/Argentina80sp/indice.htm>.

Organización de Estados Americanos. Convención Interamericana para Prevenir y Sancionar la Tortura [en línea]. OEA, 1985. [Fecha de consulta: 19/02/2019]. Disponible en $<$ http://www.oas.org/juridico/spanish/tratados/a-51.html>.

Organización Panamericana de la Salud. Informe mundial sobre la violencia y la salud: resumen. Washington: Oficina Regional para las Américas de la Organización Mundial de la Salud, 2002.

POTASH, Robert. El ejército y la política argentina. Buenos Aires: Sudamericana, 1994.

Procuración General de la Nación. Unidad Fiscal de Coordinación y Seguimiento de las Causas por Violaciones a los Derechos Humanos cometidas durante el Terrorismo de Estado. Consideraciones sobre el juzgamiento de los abusos sexuales cometidos en el marco del terrorismo de Estado [en línea]. 7 de octubre de 2011. [Fecha de consulta: 20/02/2019]. Disponible en $<$ https://www.mpf.gob.ar/docs/RepositorioW/DocumentosWeb/LinksNoticias/Delit os sexuales terrorismo de Estado.pdf>.

RICO, Nieves. Violencia de género: un problema de Derechos Humanos. Mujer y desarrollo. 1996, n. 16.

ROBIN, Marie. Escadrons De La Mort: L'Ecole Française [filme-documental]. Francia, 2003.

ROBIN, Marie. Escuadrones de la muerte: la escuela francesa. Buenos Aires: Sudamericana, 2004.

ROMÁN YÁÑEZ, César Manuel. Crítica a la concepción inmanentista de la violencia política y perspectivas sobre el terrorismo de Estado y el genocidio en la Argentina reciente. Dossier Violencia estatal, persecutoria, ideologías, terrorismo 
de estado y genocidio. Confluenze, Rivista di studi iberoamericani. 2018, vol. X, n. 2, pp. 57-79.

ROMÁN YÁÑEZ, César Manuel. Los Centros de Exterminio en la Argentina del Estado Terrorista, 1976-1983. Notas para una primera reflexión. Ponencia presentada en el I Encuentro Internacional de Estudios sobre Estados de Excepción y terrorismo de Estado [en línea]. Santiago de Compostela, 13-14 de noviembre de 2018. [Fecha de consulta: 02/05/2019]. Disponible en $<$ https://redredet.wordpress.com/>.

ROUQUIÉ, Alain. El Estado militar en América Latina. Buenos Aires: Emecé, 1984.

RUÍZ MORENO, Isidoro. Problemas actuales de la política internacional. Revista de la Escuela Superior de Guerra. 1957, n. 327, pp. 457-482.

SÁNCHEZ DE BUSTAMANTE, Tomás. La Guerra Revolucionaria. Revista de la Escuela Superior de Guerra. 1960, n. 339, pp. 602-614.

SEOANE, María y MULEIRO, Vicente. El Dictador. La historia secreta y pública de Jorge Rafael Videla. Buenos Aires: Sudamericana, 2001.

SÓNDEREGUER, María. Género y poder. Violencias de género en contextos de represión política y conflictos armados. Bernal: Universidad Nacional de Quilmes, 2012.

SÓNDEREGUER, María y CORREA, Violeta (comps.). Violencia de género en el terrorismo de Estado: políticas de memoria, justicia y reparación. Cuaderno de trabajo. Bernal: Universidad Nacional de Quilmes, 2010.

TAPIA VALDÉS, Jorge. El terrorismo de Estado: La Doctrina de la Seguridad Nacional en el Cono Sur. México: Nueva Imagen, 1980.

TOURAINE, Alaine. América Latina: Política y Sociedad. Madrid: Espasa-Calpe, 1982.

TÚROLO, Carlos. Legislar contra el comunismo. Clarín. 03/10/61.

VERTBISKY, Horacio. La solución final. Página 12 [en línea]. 03/03/95. [Fecha de consulta: 20/02/2019]. Disponible en <https://www.pagina12.com.ar/especiales/20aniversario/la solucion final.html>.

VIAGGIO, Julio. La doctrina de la seguridad nacional. Buenos Aires: Derechos del hombre, 1985.

VIDELA, Jorge Rafael. Cara a cara Videla con los periodistas. Revista Gente. 20/12/79, n. 752.

VILLEGAS, María. La violencia contra las mujeres en el marco del terrorismo de 
Estado en Argentina. Revista Derechos en Acción. 2018, vol. 9, n. 9, pp. 251265.

VILLEGAS, Osiris. Guerra Revolucionaria Comunista. Buenos Aires: Círculo Militar, 1962.

\section{Entrevistas}

Entrevista no 1. Violeta: Secuestrada el 25 febrero de 1977, en dicho momento tenía diecisiete años y era militante de la Unión de Estudiantes Secundarios.

Fecha y lugar realización de la entrevista: agosto 2012, Paraná.

Duración: 60 minutos -aproximadamente-.

Entrevista no 2. Rosa: Secuestrada el 25 de febrero de 1977, en dicho momento tenía diecinueve años y era militante de Montoneros.

Fecha y lugar realización de la entrevista: agosto 2012, Paraná.

Duración: 90 minutos -aproximadamente-.

Entrevista no 3. Celeste: Secuestrada en mayo de 1977, en dicho momento tenía veintiún años y era militante del Partido Revolucionario de los Trabajadores.

Fecha y lugar realización de la entrevista: agosto 2012, Paraná.

Duración: 90 minutos -aproximadamente-.

Entrevista $\mathrm{n}^{\circ}$ 4. Azul: Secuestrada en febrero de 1977, en dicho momento tenía veinte años y era militante de Montoneros.

Fecha y lugar realización de la entrevista: agosto 2012, Paraná.

Duración: 90 minutos -aproximadamente-. 